\title{
Usual dietary fatty acid intakes and red-blood-cell membrane fatty acid composition in Invit children attending child-care centres in Nunavik, northern Québec, Canada
}

\author{
Rosanne Blanchet ${ }^{1,2}$, Julie Lauzière ${ }^{2}$, Doris Gagné ${ }^{2}$, Carole Vézina ${ }^{2}$, Pierre Ayotte ${ }^{3}$ and \\ Huguette Turgeon $\mathrm{O}^{\prime} \mathrm{Brien}^{2, *}$ \\ 'Interdisciplinary School of Health Sciences, Faculty of Health Sciences, University of Ottawa, Ottawa, ON, \\ Canada: ${ }^{2}$ Groupe d'études en nutrition publique, Department of Food Sciences and Nutrition, Faculty of \\ Agriculture and Food Sciences, Université Laval, 2425 rue de l'Agriculture, Québec, QC GIV OA6, Canada: \\ ${ }^{3}$ Centre de recherche du Centre Hospitalier Universitaire de Québec and Université Laval, Québec, QC, Canada
}

Submitted 17 June 2013: Final revision received 17 October 2013: Accepted 29 0ctober 2013: First published online 3 December 2013

\begin{abstract}
Objectives: To assess dietary fatty acid intakes and to examine the relationship between dietary sources of $n-3$ and $n-6$ PUFA and red-blood-cell (RBC) $n-3$ and n-6 PUFA composition.

Design: A cross-sectional study. Dietary intakes were assessed with a 24 h dietary recall. A second recall was performed for $44 \%$ of the children. Usual dietary intakes were estimated with the Software for Intake Distribution Estimation (SIDE). The fatty acid composition was measured in RBC membranes. Multivariate linear regression analyses were performed to explain RBC $n-3$ and $n-6$ PUFA concentrations.

Setting: Child-care centres in Nunavik, northern Québec, Canada.

Subjects: One hundred and sixty-seven Inuit children aged 11-53 months.

Results: A high proportion of the participants had inadequate $n-3$ and $n-6$ PUFA intakes (47.9\% and $93.5 \%$, respectively). Breast-feeding status and consumption of traditional food during the first $24 \mathrm{~h}$ dietary recall were significantly associated with RBC $n$-3 PUFA levels. Older children also tended to have higher RBC $n$ - 3 PUFA levels $(P=0 \cdot 0528)$, whereas sex, infant formula status and $n$-3 PUFA dietary intakes were not associated with RBC $n$-3 PUFA concentrations. RBC $n-6$ PUFA concentrations were positively associated with breast-feeding status and n-6 PUFA dietary intakes, whereas age, sex and infant formula status were not. Conclusions: The present findings highlight the fact that Inuit pre-school children are not consuming enough $n-3$ and $n-6$ PUFA for optimum health. These observations call for actions to increase traditional food intake among Inuit children and to help them and their parents make healthier store-bought food choices.
\end{abstract}

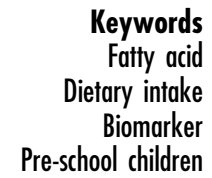

Keywords

Dietary intake

Pre-school children
Dietary fat quality is a recognized determinant of nutritional health. It is important for children to consume adequate amounts and types of fats since fatty acid (FA) intake in childhood may have important consequences for growth and development ${ }^{(1)}$. Moreover, long-chain PUFA (LC-PUFA; namely EPA (20:5n-3), docosapentaenoic acid (DPA; $22: 5 n-3)$, DHA (22:6n-3) and arachidonic acid (AA; $20: 4 n-6))$ are important for several physiological and developmental needs ${ }^{(1)}$. DHA and AA are vital structural elements of cell membranes and they are major components of the brain and retina. PUFA also play an important role in the synthesis of prostaglandins and growth hormones and in the biosynthesis of membrane components ${ }^{(1)}$. Additionally, one $n-3$ PUFA ( $\alpha$-linolenic acid
(ALA; $18: 3 n-3)$ ) and one $n$-6 PUFA (linoleic acid (LA; $18: 2 n-6))$ are essential, that is they cannot be synthesized endogenously so they must be supplied in the diet ${ }^{(2)}$. A clinical deficiency of ALA or LA causes skin problems, neurological abnormalities and poor growth ${ }^{(2)}$. However, the Institute of Medicine states that 'approximately $10 \%$ of the total $n-3$ and $n$ - 6 PUFA (ALA and LA) intakes can come from $n$ - 3 and $n$-6 LC-PUFA ${ }^{\text {(2) }}$ (p. 1325).

No biomarkers reflect absolute fat intake; however, the measurement of FA in biological samples reflects to some extent the proportional intake of $\mathrm{FA}^{(3)}$. The measurement of FA composition of red-blood-cell (RBC) membranes has been commonly used to assess PUFA intake in epidemiological studies ${ }^{(4-8)}$. Indeed, although $\operatorname{man}$ is 
technically capable of endogenously synthesizing $n-3$ LC-PUFA from ALA, this conversion is very limited and so diet is the major source of PUFA ${ }^{(3)}$.

Inuit traditional foods comprise plants and animals harvested from the local environment, mainly marine mammals, fish and seafood, land mammals and game birds ${ }^{(9)}$. Traditional foods provide many benefits to Inuit people such as cultural, social, nutritional, psychological and economic well-being ${ }^{(10)}$. However, as part of the rapid socio-cultural transition observed in Arctic Inuit populations, several studies have reported a decreased reliance on traditional foods over the last decades for the benefit of a more Western diet, especially in younger generations ${ }^{(9,11-15)}$. The ratio between $n-3$ LC-PUFA and $n-6$ PUFA is known to be a strong indicator of seafood intake and thus is a good indicator of the relative consumption of traditional food $v$. imported food among Inuit ${ }^{(16)}$. So far, most evidence regarding the dietary transition among Inuit has been obtained from dietary studies, while analyses of biomarkers of nutritional exposures have been under-represented ${ }^{(6)}$. Still, some authors have observed that Inuit have higher levels of LCPUFA in their tissues than non-Inuit ${ }^{(17-19)}$.

To the best of our knowledge, only one study described the RBC FA composition in Inuit children from the Canadian Arctic and this study was conducted more than 20 years ago ${ }^{(17)}$. The relationship between dietary sources of $n-3$ and $n-6$ PUFA and RBC $n-3$ and $n-6$ PUFA has never been assessed among Inuit children. The objectives of the present study were to assess dietary FA intakes and to examine the relationship between dietary sources of $n$ 3 and $n-6$ PUFA and RBC membrane $n-3$ and $n-6$ PUFA composition in Inuit pre-school children attending childcare centres in Nunavik.

\section{Experimental methods}

\section{Study population and data collection}

The methods have been described in detail elsewhere ${ }^{(15)}$. Briefly, this research project was a component of the Nutrition Program implemented in child-care centres of Nunavik, northern Québec, Canada, which aims to reduce Fe deficiency and improve nutrition among Inuit pre-school children. Cross-sectional data used in the present paper were collected between 2006 and 2010. Parents of Inuit children aged 1-4 years and attending a child-care centre in one of the ten Nunavik communities visited were invited to participate. Information on the study was provided to parents individually, orally or through a DVD available in Inuktitut, English and French. The study was conducted according to the guidelines laid down in the Declaration of Helsinki and all procedures involving human participants were approved by the Research Ethics Board of the Centre Hospitalier Universitaire de Québec, Québec, Canada. Written informed consent was obtained from parents/caregivers for all participants.

A total of 245 children aged 11-54 months were recruited; forty-nine were excluded from the present analyses because they did not have a $24 \mathrm{~h}$ dietary recall or because it was incomplete, fourteen were excluded because they did not have an RBC FA measurement, fourteen more had neither a complete $24 \mathrm{~h}$ dietary recall nor an RBC FA measurement, and one was lacking information about early feeding (breast-feeding and use of infant formula), which left 167 children for the present analyses.

\section{Dietary assessment}

Dietary intakes of children were assessed through the $24 \mathrm{~h}$ recall method. Each recall was completed by a registered dietitian with the parent or primary caregiver, and with cooks and educators if the child had attended a child-care centre during the day of the recall ${ }^{(15)}$. An initial $24 \mathrm{~h}$ dietary recall was obtained from each of the 167 participants. Interviews captured both weekend and weekday intakes. Three-dimensional graduated food model kits (Santé Québec) were used and information on cooking methods and brand names were obtained whenever possible. For seven participants, a standard portion was imputed based on the menu that was served because the research team did not find anyone at the child-care centre who could recall the quantity consumed by the child or his/her usual portion size. A second $24 \mathrm{~h}$ dietary recall was completed for more than $40 \%$ of the children ( $n 73)$, with two of them held over the telephone and two containing imputed portions sizes for food eaten at the child-care centre. Although we attempted not to do so, a few recalls were held on consecutive days $(n 8)$. Dietary recalls did not include specific information on nutritional supplements.

Computerization of the $24 \mathrm{~h}$ dietary recalls was done by registered dietitians at the Institut National de Santé Publique du Québec (INSPQ, Québec, QC, Canada) using the Micro Gesta software package version 1.1.56 (Micro Gesta, Québec, QC, Canada). This software is based on the Canadian Nutrient File ${ }^{(20)}$ for the nutrient content of foods. All recipes served as part of the Nutrition Program were added to the database. Also, the nutrient content of infant formulas and some new products was added manually to the database according to the information provided by manufacturers. We attributed $0 \mathrm{~g}, 447 \mathrm{~g}$ and $956 \mathrm{~g}$ of human milk to breast-fed children who had respectively $1-3,4-6$ and $\geq 7$ feedings on the reference day ${ }^{(15)}$.

\section{Blood sampling and laboratory analyses}

Blood samples $(6 \mathrm{ml})$ were collected by venepuncture into a vial containing EDTA as the anticoagulant (BD 367863; Becton Dickinson and Co., Mississauga, ON, Canada). Blood samples were either kept at room temperature for a maximum of $20 \mathrm{~min}$, kept in an insulated container with ice packs, or refrigerated at $4^{\circ} \mathrm{C}$ prior to 
processing. After centrifugation, RBC were isolated and aliquoted for FA analysis. Within $3 \mathrm{~h}$ of collection, aliquots were frozen and stored at $-18 /-20^{\circ} \mathrm{C}$. Frozen aliquots were kept in insulated containers with ice packs during transportation to the University of Guelph (Guelph, ON, Canada). The FA composition was measured in RBC membranes after membrane purification, chloroformmethanol lipid extraction ${ }^{(21)}$ and methylation of $\mathrm{FA}^{(22)}$, followed by capillary GLC using a DB-23 column (39 $\mathrm{m} \times 0.25 \mathrm{~mm}$ internal diameter $\times 0.25 \mu \mathrm{m}$ thickness) in a Varian 3400 GC. FA composition is given as the percentage of individual FA relative to the total chromatogram (\%FA).

\section{Statistical analyses}

Statistical analyses were carried out using the SAS statistical software package version $9 \cdot 2$. A $P$ value $<0 \cdot 05$ was considered statistically significant. Frequencies (\%) and means were used to describe the characteristics of participating children. To determine the distribution of usual dietary intakes, we used the Software of Intake Distribution Estimation (SIDE-IML; Iowa State University, Ames, IA, USA) to take into account the intra-individual variation in nutrient intakes. Nutrient intakes included intakes from foods and beverages. Fat and FA intakes were compared with the Acceptable Macronutrient Distribution Ranges (AMDR), which are expressed as a percentage of total energy intakes ${ }^{(2)}$. By determining the proportion of the group that falls below, within and above the AMDR, it is possible to assess population adherence to the recommendations and to determine the proportion of the population that is outside the recommended range ${ }^{(2)}$. For nutrients with an Adequate Intake (AI), methods for assessing nutrient adequacy are limited since the AI cannot be used to determine the proportion of individuals in a group with inadequate nutrient intakes ${ }^{(23)}$. However, population subgroups with mean intakes at or above the AI can be assumed to have nutritionally adequate diets ${ }^{(23)}$. Considering that only one participant was younger than 1 year of age and two participants were older than 3 years old, nutrient intakes of all participants were compared to recommendations for 1-3-year-old children.

Means were used to describe RBC FA composition and predictors of RBC $n-3$ and $n-6$ PUFA, ALA, EPA + DHA, LA and AA levels were investigated by standard linear regression. Independent variables were included in regression models if there was a priori evidence that they could be independent predictors or confounders of the outcomes. Selected variables were age, sex, breastfeeding status (never breast-fed/ever breast-fed/currently breast-fed), infant formula status (never consumed/ ever consumed/currently consuming), consumption of traditional food item (yes/no) and dietary intake of the predicted PUFA during the day of the first $24 \mathrm{~h}$ dietary recall. In additional models, we further adjusted the RBC $n-3$ and n-6 PUFA models for energy intake and BMIfor-age $Z$-score (either separately or in combination), replaced breast-feeding status by breast-feeding duration, and used dietary intakes of LA and $n-6$ PUFA as predictors of RBC n-3 PUFA. All these models explained about the same proportion of the variance in RBC $n-3$ and $n-6$ PUFA levels. For brevity, the results of these additional analyses are not presented in the form of tables.

\section{Results}

The descriptive characteristics of the study population are shown in Table 1 . The mean age of participating children was $25 \cdot 1$ (sD 9.7) months (range: 11-53 months), $40 \%$ of them were currently breast-fed or consuming an infant formula, and $34 \%$ ate at least one traditional food item during the period covered by the first $24 \mathrm{~h}$ dietary recall.

\section{Dietary intakes}

Table 2 presents estimates of the usual intake distributions for fat and FA. Participating children had higher usual intakes of SFA and MUFA than PUFA (mean: $13 \cdot 17 \%$ of energy $(\% \mathrm{E}), 11.44 \% \mathrm{E}$ and $4.45 \% \mathrm{E}$, respectively). Their usual intake of $n-6$ PUFA was more than five times higher than their usual intake of $n$-3 PUFA (mean: $3 \cdot 48 \% \mathrm{E}$ and $0 \cdot 64 \% \mathrm{E}$, respectively). The median $n-6: n-3$ PUFA was $5 \cdot 81$ and $21.0 \%$ of the children had a ratio lower than or equal to $4: 1$. Also, $31 \cdot 4 \%, 47 \cdot 9 \%$ and $93.5 \%$ of our participants fell outside the AMDR for fat, $n-3$ and $n-6$ PUFA, respectively. The vast majority of intakes tended to be below rather than above the recommended range. A minority of participants had adequate ALA and LA intake (40.4\% and $4.9 \%$, respectively).

\section{Red-blood-cell fatty acid composition}

As indicated in Table 3, the most abundant RBC FA were SFA followed by PUFA and MUFA (40 $14 \%$ FA, 35 $64 \%$ FA

Table 1 Descriptive characteristics of the participants: Inuit children aged 11-53 months ( $n$ 167) attending child-care centres, Nunavik, northern Québec, Canada

\begin{tabular}{lc}
\hline Child characteristics & Mean or \% \\
\hline Sex (\%) & \\
Boy & $52 \cdot 7$ \\
Girl & $47 \cdot 3$ \\
Age (months) & $25 \cdot 1$ \\
Breast-feeding status (\%) & $32 \cdot 9$ \\
$\quad$ Never breast-fed & $47 \cdot 3$ \\
Ever breast-fed & $19 \cdot 8$ \\
Currently breast-fed & $14 \cdot 4$ \\
Infant formula status (\%) & $65 \cdot 3$ \\
Never consumed & $20 \cdot 4$ \\
Ever consumed & $34 \cdot 1$ \\
Currently consuming & $65 \cdot 9$ \\
Consumed traditional food* (\%) & \\
Yes & $55 \cdot 7$ \\
No & $44 \cdot 3$ \\
Attended a child-care centre* (\%) & \\
Yes &
\end{tabular}


Table 2 Distributions of usual intakes of fat and FA among participants: Inuit children aged 11-53 months ( $n$ 167) attending child-care centres, Nunavik, northern Québec, Canada

\begin{tabular}{|c|c|c|c|c|c|c|c|c|c|c|}
\hline & $\begin{array}{l}\text { Fat } \\
(\% E)\end{array}$ & $\begin{array}{l}\text { SFA } \\
(\% E)\end{array}$ & $\begin{array}{c}\text { MUFA } \\
(\% \mathrm{E})\end{array}$ & $\begin{array}{c}\text { PUFA } \\
(\% \mathrm{E})\end{array}$ & $\begin{array}{c}n-3 \text { PUFA } \\
(\% \mathrm{E})\end{array}$ & $\begin{array}{c}n-6 \text { PUFA } \\
(\% \mathrm{E})\end{array}$ & $\begin{array}{l}\text { ALA } \\
(\mathrm{g} / \mathrm{d})\end{array}$ & $\begin{array}{c}\mathrm{EPA}+\mathrm{DHA} \\
(\mathrm{g} / \mathrm{d})\end{array}$ & $\begin{array}{l}\text { LA } \\
(\mathrm{g} / \mathrm{d})\end{array}$ & $\begin{array}{c}A A \\
(g / d)\end{array}$ \\
\hline 10th percentile & $26 \cdot 73$ & $9 \cdot 45$ & $9 \cdot 04$ & $3 \cdot 20$ & 0.43 & $2 \cdot 36$ & 0.48 & 0.09 & 3.09 & 0.03 \\
\hline 25th percentile & $29 \cdot 61$ & $11 \cdot 21$ & $10 \cdot 19$ & $3 \cdot 72$ & 0.51 & $2 \cdot 82$ & 0.56 & $0 \cdot 12$ & $3 \cdot 71$ & 0.05 \\
\hline Median & $32 \cdot 55$ & $13 \cdot 11$ & $11 \cdot 46$ & $4 \cdot 37$ & 0.61 & 3.39 & 0.66 & $0 \cdot 17$ & $4 \cdot 50$ & 0.09 \\
\hline Mean* & $32 \cdot 41$ & $13 \cdot 17$ & $11 \cdot 44$ & $4 \cdot 45$ & 0.64 & $3 \cdot 48$ & 0.68 & $0 \cdot 15$ & $4 \cdot 64$ & 0.11 \\
\hline 75th percentile & $35 \cdot 34$ & $15 \cdot 04$ & $12 \cdot 72$ & $5 \cdot 10$ & 0.74 & 4.05 & 0.78 & 0.24 & $5 \cdot 42$ & 0.15 \\
\hline 90th percentile & $37 \cdot 83$ & $16 \cdot 87$ & $13 \cdot 84$ & $5 \cdot 82$ & 0.88 & $4 \cdot 72$ & 0.90 & $0 \cdot 31$ & $6 \cdot 37$ & 0.24 \\
\hline AMDR or Al & $30-40$ & - & - & - & $0 \cdot 6-1 \cdot 2$ & $5-10$ & $0.7 \dagger$ & - & $7 \cdot 0+$ & - \\
\hline$\%<$ AMDR & $27 \cdot 8$ & - & - & - & 46.9 & $93 \cdot 5$ & - & - & - & - \\
\hline$\%>$ AMDR & $3 \cdot 6$ & - & - & - & $1 \cdot 0$ & 0.0 & - & - & - & - \\
\hline$\%>\mathrm{Al}$ & - & - & - & - & - & - & $40 \cdot 4$ & - & 4.9 & - \\
\hline
\end{tabular}

FA, fatty acid; \%E, percentage of energy intake; ALA, $\alpha$-linolenic acid, 18:3n-3; EPA, $20: 5 n-3$; DHA, $22: 6 n-3$; LA, linoleic acid, 18:2n-6; AA, arachidonic acid, 20:4n-6; AMDR, Acceptable Macronutrient Distribution Range; Al, Adequate Intake.

${ }^{*}$ Arithmetic mean.

tApproximately $10 \%$ of the total can come from longer-chain $n-3$ or $n-6$ PUFA.

Table 3 RBC membrane FA composition (\%FA) of Inuit children aged 11-53 months ( $n$ 167) attending child-care centres, Nunavik, northern Québec, Canada

\begin{tabular}{|c|c|c|}
\hline FA & Mean* & SD \\
\hline$\Sigma S F A$ & $40 \cdot 14$ & $5 \cdot 08$ \\
\hline $14: 0$ & 0.82 & 0.50 \\
\hline $15: 0$ & 0.28 & $0 \cdot 13$ \\
\hline $16: 0$ & $24 \cdot 78$ & $3 \cdot 48$ \\
\hline $18: 0$ & $12 \cdot 37$ & 1.58 \\
\hline $20: 0$ & 0.22 & 0.23 \\
\hline $22: 0$ & 0.58 & 0.58 \\
\hline $24: 0$ & 1.09 & 0.54 \\
\hline ¿MUFA & $24 \cdot 22$ & 3.39 \\
\hline $14: 1$ & $0 \cdot 12$ & $0 \cdot 11$ \\
\hline $16: 1$ & $1 \cdot 11$ & 0.66 \\
\hline $18: 1$ & $20 \cdot 84$ & 3.06 \\
\hline $20: 1$ & $0 \cdot 70$ & 0.91 \\
\hline $22: 1$ & $0 \cdot 36$ & 0.69 \\
\hline $24: 1$ & 1.08 & 0.52 \\
\hline ¿PUFA & $35 \cdot 64$ & $7 \cdot 54$ \\
\hline$\sum n-3$ & $5 \cdot 53$ & $2 \cdot 37$ \\
\hline $18: 3 n-3$ (ALA) & $0 \cdot 30$ & $0 \cdot 14$ \\
\hline $18: 4 n-3$ & 0.07 & $0 \cdot 18$ \\
\hline $20: 3 n-3$ & 0.02 & 0.07 \\
\hline $20: 4 n-3$ & 0.09 & $0 \cdot 14$ \\
\hline $20: 5 n-3$ (EPA) & 0.84 & 0.61 \\
\hline $22: 5 n-3$ (DPA) & $1 \cdot 54$ & 0.69 \\
\hline $22: 6 n-3(\mathrm{DHA})$ & $2 \cdot 67$ & 1.52 \\
\hline$E P A+D H A$ & $3 \cdot 51$ & 1.85 \\
\hline DPA:EPA & $2 \cdot 23$ & 0.87 \\
\hline$\Sigma n-6$ & $30 \cdot 11$ & 6.05 \\
\hline $18: 2 n-6(\mathrm{LA})$ & $15 \cdot 70$ & 3.02 \\
\hline $18: 3 n-6$ & 0.09 & $0 \cdot 11$ \\
\hline $20: 2 n-6$ & 0.31 & $0 \cdot 19$ \\
\hline $20: 3 n-6$ & 1.92 & 0.59 \\
\hline $20: 4 n-6(\mathrm{AA})$ & $10 \cdot 11$ & $3 \cdot 37$ \\
\hline $22: 2 n-6$ & 0.07 & $0 \cdot 10$ \\
\hline $22: 4 n-6$ & $1 \cdot 60$ & 0.66 \\
\hline $22: 5 n-6$ & $0 \cdot 30$ & 0.30 \\
\hline$\sum n-3: \sum n-6$ & $0 \cdot 18$ & 0.07 \\
\hline$\Sigma n-6: \Sigma n-3$ & $6 \cdot 32$ & 2.53 \\
\hline ¿SFA: PUFA & $1 \cdot 24$ & 0.55 \\
\hline
\end{tabular}

RBC, red-blood-cell; FA, fatty acid; \%FA, percentage of individual FA relative to the total chromatogram; ALA, $\alpha$-linolenic acid; DPA, docosapentaenoic acid; $\mathrm{LA}$, linoleic acid; $\mathrm{AA}$, arachidonic acid.

${ }^{*}$ Arithmetic mean.

and $24 \cdot 22 \% \mathrm{FA}$, respectively). The two major SFA were $16: 0$ and 18:0, whereas the major MUFA was 18:1. LA and AA were the major $n-6$ PUFA $(15 \cdot 70 \%$ FA and $10 \cdot 11 \%$ FA, respectively), whereas DHA and DPA were the major $n$-3 PUFA $(2 \cdot 67 \% \mathrm{FA}$ and $1.54 \% \mathrm{FA}$, respectively). ALA and EPA contributed less than $1 \%$ of the total RBC FA $(0 \cdot 30 \% \mathrm{FA}$ and $0 \cdot 84 \% \mathrm{FA}$, respectively). Mean RBC DPA:EPA and $n-6: n-3$ PUFA were $2 \cdot 23$ and $6 \cdot 32$, respectively.

\section{Multivariate models}

Table 4 presents multivariate regression models explaining RBC $n-3$ and $n-6$ PUFA, ALA, EPA + DHA and LA concentrations. The consumption of at least one traditional food item during the initial $24 \mathrm{~h}$ dietary recall (yes/no) and breast-feeding status (never breast-fed/ever breast-fed/ currently breast-fed) were significant positive predictors of RBC $n$-3 PUFA $(P=0 \cdot 0080$ and $P=0 \cdot 0243$, respectively). Older children also tended to have higher RBC $n$-3 PUFA ( $P=0 \cdot 0528$ ), whereas sex, infant formula status (never consumed/ever consumed/currently consuming) and $n-3$ PUFA dietary intakes during the day of the first $24 \mathrm{~h}$ dietary recall were not associated with RBC $n-3$ PUFA. Neither LA nor $n-6$ PUFA dietary intakes were associated with RBC $n$-3 PUFA, nor were $n-3$ PUFA dietary intakes associated with RBC $n-6$ PUFA (data not shown). RBC $n-6$ PUFA concentrations were positively explained by breast-feeding status and $n$-6 PUFA dietary intakes during the day of the first $24 \mathrm{~h}$ dietary recall $(P=0 \cdot 0222$ and $P=0 \cdot 0108$, respectively), whereas no significant associations were found with age, sex and infant formula status. These models accounted for $11-13 \%$ of the variance in RBC $n-3$ and $n-6$ PUFA concentrations. Further adjusting for energy intake or BMI-for-age $Z$-score did not improve models and these variables were not significantly associated with RBC $n-3$ or $n-6$ PUFA concentrations (data not shown). Finally, when breast-feeding status was replaced by breast-feeding duration in these models, a positive and significant association was observed with RBC $n-3$ PUFA but not with RBC n-6 PUFA (data not shown). Models explaining RBC ALA, $\mathrm{EPA}+\mathrm{DHA}$ and LA concentrations were very similar to the models explaining $n-3$ and $n-6$ PUFA except for age, which was significantly associated with RBC EPA+DHA levels $(P=0 \cdot 0306)$. None of the models tested for RBC AA level reached statistical significance. 
Table 4 Multivariate linear regression of factors explaining RBC membrane $n-3$ and $n-6$ PUFA concentrations in Inuit children aged 11-53 months ( $n$ 167) attending child-care cntres, Nunavik, northern Québec, Canada

\begin{tabular}{|c|c|c|c|c|}
\hline RBC membrane concentration & Predictors & $\beta$ & $P$ & $R^{2}$ \\
\hline$n-3$ PUFA & $\begin{array}{l}\text { Age (months) } \\
\text { Sex (girl/boy) } \\
\text { Breast-feeding status* } \\
\text { Infant formula statust } \\
\text { Consumed traditional food } \neq \text { (no/yes) } \\
n-3 \text { PUFA dietary intake } \neq(\mathrm{g})\end{array}$ & $\begin{array}{r}0.04 \\
0.33 \\
0.61 \\
-0.24 \\
1.02 \\
-0.15\end{array}$ & $\begin{array}{l}0.0528 \\
0.3560 \\
0.0243 \\
0.4643 \\
0.0080 \\
0.5895\end{array}$ & \\
\hline ALA & $\begin{array}{l}\text { Age (months) } \\
\text { Sex (girl/boy) } \\
\text { Breast-feeding status* } \\
\text { Infant formula statust } \\
\text { Consumed traditional food } ¥ \text { (no/yes) } \\
\text { ALA dietary intake }(g)\end{array}$ & $\begin{array}{r}-0.00 \\
0.00 \\
0.03 \\
-0.04 \\
0.02 \\
-0.03\end{array}$ & $\begin{array}{l}0.9735 \\
0.9362 \\
0.0520 \\
0.0252 \\
0.3660 \\
0.6644\end{array}$ & $0 \cdot 11$ \\
\hline $\mathrm{EPA}+\mathrm{DHA}$ & $\begin{array}{l}\text { Age (months) } \\
\text { Sex (girl/boy) } \\
\text { Breast-feeding status* } \\
\text { Infant formula statust } \\
\text { Consumed traditional food } ¥ \text { (no/yes) } \\
\text { ALA dietary intake }(\mathrm{g}) \\
\text { EPA+DHA dietary intake } ¥ \mathrm{~g})\end{array}$ & $\begin{array}{r}0.03 \\
0.08 \\
0.54 \\
-0.06 \\
0.71 \\
-0.44 \\
-0.15\end{array}$ & $\begin{array}{l}0.0306 \\
0.7641 \\
0.0107 \\
0.8187 \\
0.0208 \\
0.6495 \\
0.6832\end{array}$ & 0.08 \\
\hline$n-6$ PUFA & $\begin{array}{l}\text { Age (months) } \\
\text { Sex (girl/boy) } \\
\text { Breast-feeding status* } \\
\text { Infant formula statust } \\
n-6 \text { PUFA dietary intake }(\mathrm{g})\end{array}$ & $\begin{array}{r}-0.04 \\
-1.56 \\
1.55 \\
1.51 \\
0.43\end{array}$ & $\begin{array}{l}0.4038 \\
0 \cdot 0821 \\
0 \cdot 0222 \\
0 \cdot 0804 \\
0 \cdot 0108\end{array}$ & $0 \cdot 10$ \\
\hline LA & $\begin{array}{l}\text { Age (months) } \\
\text { Sex (girl/boy) } \\
\text { Breast-feeding status* } \\
\text { Infant formula statust } \\
\text { LA dietary intake }(\mathrm{g})\end{array}$ & $\begin{array}{r}-0.01 \\
-1.29 \\
1.21 \\
0.52 \\
0.24\end{array}$ & $\begin{array}{l}0.5822 \\
0.0030 \\
0.0002 \\
0.2059 \\
0.0040\end{array}$ & 0.13 \\
\hline
\end{tabular}

RBC, red-blood-cell; ALA, $\alpha$-linolenic acid; LA, linoleic acid.

${ }^{\star}$ Never breast-fed/ever breast-fed/currently breast-fed.

tNever consumed/ever consumed/currently consuming.

‡During the day of the first $24 \mathrm{~h}$ dietary recall.

\section{Discussion}

\section{Dietary intakes}

A significant proportion (31\%) of our participants had a usual fat intake that fell outside the AMDR set at 30-40\%E for children aged 1-3 years. This proportion was at the lower end of those observed in representative groups of Canadian and US children of the same age $(23-50 \% \mathrm{E})^{(24-27)}$. Also, in agreement with these studies, we found that more than a quarter of our participants $(27 \cdot 8 \%)$ had a usual fat intake below the AMDR, with only a small proportion above the higher limit of the AMDR. According to the Institute of Medicine, there is no evidence that the macronutrient composition of the diet affects childhood growth if energy and protein requirements are met ${ }^{(2)}$. This seems to be the case among our participants as only $1 \cdot 4 \%$ had a protein intake below the Estimated Average Requirement $(\mathrm{H}$ Turgeon O'Brien, D Gagné, É Vaissière et al., unpublished results). Moreover, the mean fat intake $(32 \% \mathrm{E})$ in the present study was in the range of values reported in a systematic review of fat and FA intakes of children and adolescents around the world $(23-40 \% \mathrm{E})^{(28)}$. Mean usual intakes of SFA and MUFA were also similar to levels observed in a representative sample of 1-3-year-old Canadian children ${ }^{(25)}$, whereas the usual intake of PUFA was slightly higher among our participants $(4 \cdot 5 \% \mathrm{E} v$. $3 \cdot 8 \% \mathrm{E}$, respectively). Mean usual intakes of SFA and PUFA were also within the range observed by Harika et al. among children worldwide $(1 \cdot 0-15 \cdot 2 \% \mathrm{E}$ and $3 \cdot 5-9 \cdot 7 \%$ E, respectively) ${ }^{(28)}$. When compared with a representative group of Inuit adults who participated in the Nunavik Inuit Health Study (NIHS), total fat and MUFA contributed a similar proportion to energy intake but PUFA contributed a slightly lower proportion to energy intake $(4.5 \% \mathrm{E} v .5 \% \mathrm{E} \text { in NIHS, respectively })^{(13)}$. In the same way, $n-3$ and n-6 PUFA usual dietary intakes of participants in the present study were almost half those in NIHS ${ }^{(13)}$. However, our participants had the same median $n$-6:n-3 PUFA dietary intake ratio ${ }^{(13)}$. The sum of dietary intakes of EPA + DHA $(0 \cdot 15 \mathrm{~g} / \mathrm{d})$ was similar to that observed in a group of 3 -5-year-old Canadian children from Vancouver $(0 \cdot 14 \mathrm{~g} / \mathrm{d})^{(29)}$ and within the 
range observed in children worldwide $(0 \cdot 05-0 \cdot 15 \mathrm{~g} / \mathrm{d})^{(28)}$. Concerning essential FA, the proportion of children with adequate usual intakes ( $>$ AI) of ALA and LA in the present study was lower than in Canadian children and Canadian Inuit adults (ALA: 40\%, 69\% and 75-90\%, respectively; LA: $5 \%, 21 \%$ and $2-29 \%$, respectively) $)^{(30-32)}$. Altogether, these results reiterate that Inuit pre-school children rely less on traditional foods than Inuit adults ${ }^{(15)}$ and indicate that their FA dietary intakes are similar to those of children worldwide.

\section{Red-blood-cell fatty acid composition}

RBC $n-6$ and $n$-3 PUFA were higher in our participants than in US children aged $1-11$ years $(30 \cdot 11 \% \mathrm{FA} v \cdot 24 \cdot 93 \% \mathrm{FA}$ and $5 \cdot 53 \% \mathrm{FA} v \cdot 3 \cdot 81 \% \mathrm{FA}$, respectively) ${ }^{(7)}$. Although RBC PUFA composition of Danish adolescents was similar to that of our participants, the former had higher levels of LC-PUFA $^{(8)}$. Canadian Inuit children living on Broughton Island (formerly in Northwest Territories, now in Nunavut) and aged $0-5$ years in 1985 ( $n$ 13) had probably higher levels of $n-3$ LC-PUFA, although it is uncertain because concentrations of RBC FA were reported for phosphatidylcholine and phosphatidylethanolamine separately ${ }^{(17)}$.

The ratio of $n-6$ to $n-3$ PUFA has been used as an indicator of dietary Westernization among Indigenous people, with higher ratios indicating lower consumption of traditional foods ${ }^{(33)}$. In our study, we observed a high $n-6: n-3$ PUFA, confirming our previous observation on the dietary transition and the lower reliance upon traditional foods $^{(15)}$. Moreover, Zhou et al. suggested that a high DPA:EPA might be a novel indicator of a diet containing a larger proportion of land animals than of both fish and marine mammals ${ }^{(6)}$. We observed a higher DPA:EPA than the ones reported by Zhou et al. in all the communities they surveyed, which would suggest that our participants may have consumed more land animals than fish and marine mammals. If we look more closely, we can see that this high ratio is explained by lower RBC EPA levels among our participants rather than higher levels of DPA. Therefore, this result seems to be more indicative of a low consumption of fish and marine mammals rather than of a high consumption of land animals. Indeed, when considering multiple indicators, we conclude that these young Inuit children eat a lower proportion of traditional food and more specifically a lower amount of fish and marine mammals than Inuit adults.

\section{Multivariate models}

In the regression models, we showed that breast-feeding status (never breast-fed/ever breast-fed/currently breastfed) was positively associated with RBC $n-3$ and $n-6$ PUFA concentrations. This is in agreement with the positive association observed between breast-feeding duration and RBC DHA and EPA levels in Danish adolescents ${ }^{(8)}$. When replacing breast-feeding status by breast-feeding duration, we observed a positive and significant association with RBC $n-3$ PUFA but not with RBC $n-6$ PUFA. This result may suggest that breast-feeding duration may be indicative of a more traditional lifestyle containing more $n$-3 LC-PUFA than $n$-6 LC-PUFA after weaning ${ }^{(34)}$.

In the model explaining RBC $n-3$ PUFA, dietary $n-3$ PUFA intake was not significantly associated. This is in agreement with Hoyos et al., who did not observe a significant association between $n$-3 PUFA dietary intake and plasma $n$-3 PUFA in 18- and 36-month-old Australian children ${ }^{(35)}$. On the contrary, we observed that the consumption of traditional foods during the $24 \mathrm{~h}$ dietary recall period was associated with higher RBC $n$-3 PUFA levels. This may suggest that having consumed a traditional food may be a better indicator of a traditional diet than $n$-3 PUFA or EPA + DHA dietary intakes when assessed with a $24 \mathrm{~h}$ dietary recall. Indeed, we have previously hypothesized that it might be harder to report traditional food serving sizes of young children as they are often served or taken by hand, one mouthful at a time, from a centre dish, with other family members (or childcare centre staff) participating in the service and that this could lead to misestimating traditional food intakes ${ }^{(15)}$. The positive association between the consumption of traditional food and RBC $n-3$ PUFA is also in accordance with results from Lucas et al., who observed that intakes of most Inuit traditional foods (marine mammals, fish, land animals and game-bird eggs) were correlated with RBC $n-3$ LC-PUFA in Nunavik adults ${ }^{(4)}$. Young et al. also reported a positive association between the consumption of traditional foods and plasma EPA and DHA among adults $^{(18)}$. In the present study, age also tended to be significantly associated with RBC $n$-3 PUFA levels and was significantly associated with RBC EPA+DHA, which is agreement with increased plasma $n-3$ LC-PUFA observed in 36- and 60-month-old children compared with the same children at age 24 months $^{(36)}$. Sex and infant formula status were not significantly associated with RBC $n-3$ PUFA. It has been hypothesized that intake of LA or $n-6$ PUFA may blunt the tissue incorporation of $n-3$ PUFA $^{(35,37)}$ but their intakes were not associated with RBC $n$-3 PUFA in our study. We did not observe any relationship between BMI-for-age Z-score and RBC $n$ - 3 PUFA levels; this differs from Burrows et al. who had suggested a role for $n$-3 LCPUFA in the development of obesity as they observed lower levels of RBC EPA+DHA among obese Australian children compared with non-obese ${ }^{(38)}$. As for RBC $n-6$ PUFA levels, they were positively associated with breast-feeding status as mentioned above and, as expected, with $n-6$ PUFA dietary intakes. In 18- and 36-month-old Australian children, dietary $n$-6 PUFA were also positively associated with plasma $n-6$ PUFA levels ${ }^{(35)}$. Age, sex and infant formula status were not associated with RBC $n-6$ PUFA concentrations.

\section{Limitations}

When interpreting the present results, one ought to keep in mind the limits of the study. First, to estimate usual 
dietary intakes, SIDE requires that individuals must be independent. This was not always true in the present study as some siblings were recruited. Unfortunately, this information was not collected, preventing us from adjusting for this variable. Also, as reported elsewhere ${ }^{(15)}$, children in the present study had a lower energy intake compared with a representative group of Canadian children of the same age group participating in the 2004 Canadian Community Health Survey (CCHS). Even though parents in the CCHS were believed to have overestimated the dietary intakes of their children ${ }^{(39)}$, there is a possibility that energy intake was under-reported in our participants and this could have increased the prevalence of inadequate nutrient intakes in our study ${ }^{(40)}$. Moreover, we may have induced a selection bias since children included in the present analyses (i.e. those with a complete set of variables) represent $68 \cdot 2 \%$ of enrolled participants.

Another limit of our study includes the use of a $24 \mathrm{~h}$ dietary recall to estimate FA dietary intakes. The $24 \mathrm{~h}$ dietary recall method is a simple, rapid and wellestablished tool to assess the average intake of groups ${ }^{(41)}$. We collected a second recall for a significant proportion of the children to improve the accuracy of individual intake estimates and take intra-individual variability into account. However, in multivariate models, we had to use only the first $24 \mathrm{~h}$ dietary recall because we did not have enough recalls per children to represent usual dietary intakes on an individual basis. For example, sixty-four recalls per adults are necessary to estimate individual usual intakes of total fat ${ }^{(42)}$. Therefore dietary intakes included in regression models may not represent the usual intakes of children. Moreover, our results also depend on the Canadian Nutrient File for data analysis ${ }^{(20)}$ which has its own limits. Indeed, the version used did not cover all foods for $n-3$ and n-6 PUFA, and there might be more variation among wild animals resulting in higher or lower dietary intakes than estimated by the Canadian Nutrient File. Furthermore, a measure of dietary intakes covering a longer period of time would have been optimal to compare with exposure reflected by the RBC FA concentrations. The fact that we used a $24 \mathrm{~h}$ dietary recall could have lowered the strength of the relationships between dietary intakes and RBC levels, especially for $n$-3 LC-PUFA. However, using an FFQ covering a longer period of time was difficult with our population as some children had only commenced eating solids during the last 12 months, which was the period covered by the FFQ; limiting our capacity to use it. The uncertainty in the present study is therefore presumed to be mainly related to the dietary assessment, while assessment of RBC membranes reflects the general intake over the lifespan of $\mathrm{RBC}$, or $\sim 120 \mathrm{~d}^{(3,43)}$. Still, FA in RBC membranes are under the control of both genetic and other modifying factors such as disease and nutritional status, although RBC PUFA respond to differences in dietary intake more so than do RBC SFA ${ }^{(3,43)}$.

\section{Conclusions}

Findings from the present study confirm that diet is a major determinant of RBC FA composition in Canadian Inuit. Indeed, n-6 PUFA dietary intake assessed with a $24 \mathrm{~h}$ dietary recall and breast-feeding status explained part of the variation of RBC $n-6$ PUFA levels among these Inuit pre-school children. Also, even if $n$-3 PUFA dietary intake was not significantly associated with RBC $n$-3 PUFA levels, the consumption of traditional food during the initial $24 \mathrm{~h}$ dietary recall and breast-feeding status were identified as significant predictors. The present findings also highlight the fact that Inuit pre-school children are not consuming enough $n$-3 LC-PUFA for optimum health and corroborate the intergenerational trend towards younger Inuit now depending more on store-bought foods than their parents. This is of concern, as the replacement of a traditional diet with a Western diet may increase the risk of $\mathrm{CVD}^{(5,6)}$ and have detrimental consequences on growth and development ${ }^{(1)}$. However, it is important to recognize that store-bought food choices - but not store-bought food per se-influence FA profiles ${ }^{(32)}$. These observations call for actions to increase traditional food intake among Inuit children and to help them and their parents make healthier store-bought food choices.

\section{Acknowledgements}

Sources of funding: This study was made possible through funding by the Aboriginal Affairs and Northern Development Canada Canada-Northern Contaminants Program, Kativik Regional Government and Health Canada. Aboriginal Affairs and Northern Development Canada Canada-Northern Contaminants Program, Kativik Regional Government and Health Canada had no role in the design, analysis or writing of this article. Conflicts of interest: The authors declare that they have no conflicts of interest. Authors' contributions: R.B. conducted the statistical analyses, interpreted the results and prepared the first draft of the manuscript; J.L. contributed to the interpretation of the results and participated in the drafting of the manuscript; D.G., C.V., H.T.O. and P.A. were responsible for the study idea and design; H.T.O. contributed to the interpretation of the data and drafting the manuscript. All authors read and approved the final manuscript. Acknowledgements: The authors are grateful to the Nunavik parents and children for their participation. They also wish to thank all educators, cooks and directors of child-care centres in Nunavik, who were very supportive of the project.

\section{References}

1. Huffman SL, Harika RK, Eilander A et al. (2011) Essential fats: how do they affect growth and development of infants and young children in developing countries? A literature review. Matern Child Nutr 7, Suppl. 3, S44-S65. 
2. Institute of Medicine (2005) Dietary Reference Intakes for Energy, Carbohydrates, Fiber, Fat, Fatty Acids, Cholesterol, Protein, and Amino Acids. Washington, DC: National Academies Press.

3. Arab L (2003) Biomarkers of fat and fatty acid intake. J Nutr 133, Suppl. 3, S925-S932.

4. Lucas M, Proust F, Blanchet C et al. (2010) Is marine mammal fat or fish intake most strongly associated with omega-3 blood levels among the Nunavik Inuit? Prostaglandins Leukot Essent Fatty Acids 83, 143-150.

5. Bersamin A, Luick BR, King IB et al. (2008) Westernizing diets influence fat intake, red blood cell fatty acid composition, and health in remote Alaskan Native communities in the center for Alaska Native health study. $J$ Am Diet Assoc 108, 266-273.

6. Zhou YE, Kubow S \& Egeland GM (2011) Highly unsaturated $n-3$ fatty acids status of Canadian Inuit: International Polar Year Inuit Health Survey, 2007-2008. Int J Circumpolar Health 70, 498-510.

7. Orton HD, Szabo NJ, Clare-Salzler M et al. (2008) Comparison between omega-3 and omega- 6 polyunsaturated fatty acid intakes as assessed by a food frequency questionnaire and erythrocyte membrane fatty acid composition in young children. Eur J Clin Nutr $\mathbf{6 2}$, 733-738.

8. Lauritzen L, Harslof LB, Hellgren LI et al. (2012) Fish intake, erythrocyte $n-3$ fatty acid status and metabolic health in Danish adolescent girls and boys. Br J Nutr 107, 697-704.

9. Kuhnlein HV, Soueida R \& Receveur O (1996) Dietary nutrient profiles of Canadian Baffin Island Inuit differ by food source, season, and age. J Am Diet Assoc 96, 155-162.

10. Kuhnlein HV \& Receveur O (1996) Dietary change and traditional food systems of indigenous peoples. Annu Rev Nutr 16, 417-442.

11. Egeland GM, Berti P, Soueida R et al. (2004) Age differences in vitamin A intake among Canadian Inuit. Can J Public Health 95, 465-469.

12. Kuhnlein HV \& Receveur O (2007) Local cultural animal food contributes high levels of nutrients for Arctic Canadian indigenous adults and children. J Nutr 137, 1110-1114

13. Blanchet C \& Rochette L (2008) Nutrition Inuit Health Survey 2004, Qanuippitaa? How Are We?: Nutrition and Food Consumption Among the Inuit of Nunavik. Québec: Institut National de la Santé Publique du Québec \& Nunavik Regional Board of Health and Social Services.

14. Johnson-Down L \& Egeland GM (2010) Adequate nutrient intakes are associated with traditional food consumption in Nunavut Inuit children aged $3-5$ years. J Nutr 140, 1311-1316.

15. Gagné D, Blanchet R, Lauzière J et al. (2012) Traditional food consumption is associated with higher nutrient intakes in Inuit children attending childcare centres in Nunavik. Int J Circumpolar Health 71, 18401.

16. Deutch B, Pedersen HS \& Hansen JC (2004) Dietary composition in Greenland 2000, plasma fatty acids and persistent organic pollutants. Sci Total Environ 331, $177-188$.

17. Innis SM, Kuhnlein HV \& Kinloch D (1988) The composition of red cell membrane phospholipids in Canadian Inuit consuming a diet high in marine mammals. Lipids 23, $1064-1068$

18. Young TK, Gerrard JM \& O'Neil JD (1999) Plasma phospholipid fatty acids in the central Canadian arctic: biocultural explanations for ethnic differences. Am J Phys Anthropol 109, 9-18.

19. Dewailly E, Blanchet C, Gingras S et al. (2003) Fish consumption and blood lipids in three ethnic groups of Quebec (Canada). Lipids 38, 359-365.
20. Health Canada (2007) Canadian Nutrient File, Version 2007b. http://www.hc-sc.gc.ca/fn-an/nutrition/fiche-nutridata/index-eng.php

21. Folch J, Lees M \& Sloane Stanley GH (1957) A simple method for the isolation and purification of total lipids from animal tissues. J Biol Chem 226, 497-509.

22. Morrison WR \& Smith LM (1964) Preparation of fatty acid methyl esters and dimethylacetals from lipids with boron fluoride-methanol. I Lipid Res 1964, 600-608.

23. Institute of Medicine, Food and Nutrition Board (2010) Dietary Reference Intakes: Applications in Dietary Assessment. Washington, DC: National Academies Press.

24. Butte NF, Fox MK, Briefel RR et al. (2010) Nutrient intakes of US infants, toddlers, and preschoolers meet or exceed dietary reference intakes. J Am Diet Assoc 110, Suppl. 12, S27-S37.

25. Health Canada (2008) Canadian Community Health Survey, Cycle 2.2, Nutrition (2004): Nutrient Intakes from Food. Provincial, Regional and National Summary Data Tables, Vol. 1. Ottawa: Health Canada \& Statistics Canada.

26. Devaney B, Ziegler P, Pac S et al. (2004) Nutrient intakes of infants and toddlers. J Am Diet Assoc 104, Suppl. 1, S14-S21.

27. Troiano RP, Briefel RR, Carroll MD et al. (2000) Energy and fat intakes of children and adolescents in the United States: data from the national health and nutrition examination surveys. Am J Clin Nutr 72, Suppl. 5, S1343-S1353.

28. Harika RK, Cosgrove MC, Osendarp SJ et al. (2011) Fatty acid intakes of children and adolescents are not in line with the dietary intake recommendations for future cardiovascular health: a systematic review of dietary intake data from thirty countries. Br J Nutr 106, 307-316.

29. Innis SM, Vaghri Z \& King DJ (2004) $n-6$ Docosapentaenoic acid is not a predictor of low docosahexaenoic acid status in Canadian preschool children. Am J Clin Nutr 80, 768-773.

30. Health Canada (2009) Canadian Community Health Survey, Cycle 2.2, Nutrition (2004): Nutrient Intakes from Food. Provincial, Regional and National Summary Data Tables, Vol. 2. Ottawa: Health Canada \& Statistics Canada.

31. Health Canada (2009) Canadian Community Health Survey, Cycle 2.2, Nutrition (2004): Nutrient Intakes from Food. Provincial, Regional and National Summary Data Tables, Vol. 3. Ottawa: Health Canada \& Statistics Canada.

32. Kuhnlein HV, Receveur O, Soueida R et al. (2007) Unique patterns of dietary adequacy in three cultures of Canadian Arctic Indigenous Peoples. Public Health Nutr 5, 1-12.

33. Simopoulos AP (2008) The omega-6/omega-3 fatty acid ratio, genetic variation, and cardiovascular disease. Asia Pac J Clin Nutr 17, Suppl. 1, S131-S134.

34. Kuhnlein HV, Chan HM, Leggee D et al. (2002) Macronutrient, mineral and fatty acid composition of Canadian Arctic Traditional Food. J Food Compost Anal 15, 545-566.

35. Hoyos C, Almqvist C, Garden F et al. (2008) Effect of omega 3 and omega 6 fatty acid intakes from diet and supplements on plasma fatty acid levels in the first 3 years of life. Asia Pac J Clin Nutr 17, 552-557.

36. Guerra A, Demmelmair H, Toschke AM et al. (2007) Threeyear tracking of fatty acid composition of plasma phospholipids in healthy children. Ann Nutr Metab 51, 433-438.

37. Hibbeln JR, Nieminen LR, Blasbalg TL et al. (2006) Healthy intakes of $n-3$ and $n-6$ fatty acids: estimations considering worldwide diversity. Am J Clin Nutr 83, Suppl. 6, S1483-S1493.

38. Burrows T, Collins CE \& Garg ML (2011) Omega-3 index, obesity and insulin resistance in children. Int J Pediatr Obes 6. E532-E539. 
39. Health Canada (2006) Canadian Community Health Survey, Cycle 2.2, Nutrition (2004): A Guide to Accessing and Interpreting the Data. Ottawa: Health Canada.

40. Gibson RS (2005) Principles of Nutritional Assessment, 2nd ed. New York: Oxford University Press, Inc.

41. Willett W (1998) Nutritional Epidemiology, 2nd ed. New York: Oxford University Press.
42. Basiotis PP, Welsh SO, Cronin FJ et al. (1987) Number of days of food intake records required to estimate individual and group nutrient intakes with defined confidence. $J$ Nutr 117, 1638-1641.

43. Hodson L, Skeaff CM \& Fielding BA (2008) Fatty acid composition of adipose tissue and blood in humans and its use as a biomarker of dietary intake. Prog Lipid Res 47, 348-380. 